\title{
A Comprehensive Study of the Solubility, Thermochemistry, Ion Exchange, and Precipitation Kinetics of $\mathrm{NO}_{3}$ Cancrinite and $\mathrm{NO}_{3}$ Sodalite (Project \#: 81959)
}

Principal Investigator (PI):

Dr. Carlos F. Jove Colon

Total System Performance Assessment (TSPA)

Sandia National Laboratories

P.O. Box 5800 MS MS 0778

Albuquerque, NM 87185-0778 USA

505-284-5494

e-mail: cfjovec@sandia.gov

Co-PI's

Prof. Alexandra Navrotsky

Thermochemistry Facility

Dept. of Chemical Engineering

and Material Sciences

University of California

Davis, CA 95616 USA

530-752-9289

e-mail: anavrotsky@ucdavis.edu

Dr. James L. Krumhansl

Geochemistry Dept.

Sandia National Laboratories

P.O. Box 5800 MS 0750

Albuquerque, NM 87185-0750 USA

505-844-9093

e-mail: jlkrumh@sandia.gov

Dr. May Nyman

Geochemistry Dept.

Sandia National Laboratories

P.O. Box 5800 MS 0750

Albuquerque, NM 87185-0750 USA

Thermochemistry Facility

Dept. of Chemical Engineering

and Material Sciences

University of California

Davis, CA 95616 USA

530-752-1842

email: qliu@ucdavis.edu

Dr. François Bonhomme 
Geochemistry Dept.

Sandia National Laboratories

P.O. Box 5800 MS 0750

Albuquerque, NM 87185-0750 USA

Dr. Todd Alam

Organic Materials Dept.

Sandia National Laboratories

MS 0888

Albuquerque, NM 87185-0888 USA

505-844-1225

e-mail: tmalam@sandia.gov

Dr. Brian R. Cherry

Organic Materials Dept.

Sandia National Laboratories

MS 0888

Albuquerque, NM 87185-0888 USA

505-284-3737

e-mail:brcherr@sandia.gov 
Research Objective: $\mathrm{NO}_{3}$ cancrinite and $\mathrm{NO}_{3}$ sodalite haves been found as a common sodium alumino-silicate forming in strongly caustic alkaline aqueous solutions associated with radioactive High Level Waste (HLW) stored in many underground tanks and also in nuclear waste treatment facilities such as the Savannah River Site (SRS). The precipitation of alumino-silicate phases from caustic nuclear wastes has proven to be problematic in a number of processes in waste treatment facilities including radionuclide separations (cementation of columns by aluminosilicate phases), tank emptying (aluminosilicate tank heels), and condensation of wastes in evaporators (aluminosilicate precipitates in the evaporators, providing nucleation sites for growth of critical masses of radioactive actinide salts). Therefore, in order to prevent their formation an assessment of the relative stability, formation kinetics, and the ion-exchange characteristics of these two phases in HLW solutions needs to be investigated. The goals of this project are to:

- Develop a robust equilibrium thermodynamic framework to accurately describe and predict the formation of $\mathrm{NO}_{3}$ cancrinite and $\mathrm{NO}_{3}$ sodalite.

- Provide a comprehensive characterization of the solid precipitation rates and mechanisms using novel spectroscopic (e.g., NMR) and thermochemical techniques in conditions encountered in HLW waste solutions.

- Characterize the precipitation kinetics of the aluminosilicates and study the effects of temperature and fluid composition.

- Investigate the ion exchange capacity of these zeolitic phases with respect to radionuclides and RCRA metal species.

Research Progress and Implications: This report summarizes the results of the past year work. To date, the following achievements have been accomplished:

- Synthesis and characterization of $\mathrm{NO}_{3}$ cancrinite and sodalite. Structural characterization and refinement of multiple syntheses of $\mathrm{NO}_{3}$ cancrinite has been obtained by using X-Ray Powder Diffraction (XRPD) data and Rietveld analysis. Structural parameter data obtained from these refinements have been compared to that of published studies confirming the purity of the syntheses. Many attempts to synthesize $\mathrm{NO}_{3}$ sodalite resulted in a phase with the sodalite structure but with both $\mathrm{NO}_{3}$ and carbon. The latter appears to be present as an impurity. Further experiments are planned to produce a pure $\mathrm{NO}_{3}$ sodalite. Assessment of amorphous content in the syntheses using Rietveld refinement of XRPD data indicated a highly crystalline run product. We are also currently investigating the compositional and structural variations of the hydroxysodalites by synthesis, ion exchange, and spectroscopic characterizations including FTIR, XRPD and solidstate NMR $\left({ }^{29} \mathrm{Si},{ }^{1} \mathrm{H},{ }^{27} \mathrm{Al},{ }^{23} \mathrm{Na}\right)$. Hydroxysodalites have the general formula:

$$
\mathrm{Na}_{8-\mathrm{x}}\left[\mathrm{SiAlO}_{4}\right]_{6}(\mathrm{OH})_{2-\mathrm{x}} \bullet \mathrm{yH}_{2} \mathrm{O} \quad(\mathrm{x}=0-2 ; \mathrm{y}=0-2) .
$$

We are also investigating partially or fully substituting $\mathrm{NO}_{3}{ }^{-}$into the $\mathrm{OH}^{-}$site. Figure 3 shows XRPD, FTIR and ${ }^{29} \mathrm{Si}$ (direct and ${ }^{1} \mathrm{H}$-cross polarized) of a series of hydroxysodalites. Sample $\mathbf{A}$ is hydroxysodalite with $\mathrm{x}=0$, and we are yet uncertain the amount of water within the pores (y). Samples B-E were prepared by contact of $\mathbf{A}$ with 1 molar $\mathrm{NH}_{4} \mathrm{NO}_{3}$ (ammonium nitrate) solution at $70{ }^{\circ} \mathrm{C}$ for 10 (B), 20 (C), 30 (D) and 60 (E) minutes. This treatment results in no incorporation of nitrate into the sodalite pores, as indicated by ion chromatography and FTIR. Sample A by IR spectroscopy appears to have 
essentially no water within the pores $(y=0)$, by the lack of the broad water vibrations around 3500 and 1600 wavenumbers, and we will investigate this further by ${ }^{1} \mathrm{H}$ NMR experiments. XRPD of hydroxysodalite treated with ammonium nitrate (samples B-E) show split peaks, with increasing intensity in the new set of peaks with increasing treatment time. This same change in the Xray diffraction pattern is observed when hydroxysodalite is treated with nitric acid solution, but $\sim 80-90 \%$ of the sample dissolves as a result of this treatment. This suggests that the peak splitting resulting from these treatments is either a function of $\mathrm{Na}$ ? $\mathrm{H}$ exchange, or extraction of $\mathrm{NaOH}$ from the framework. Further investigations by NMR will provide more insight to these characterizations. By direct ${ }^{29} \mathrm{Si}$ NMR, we see one peak for sample $\mathbf{A}$, corresponding with one crystallographic $\mathrm{SiO}_{4}$ site. In samples $\mathbf{B}-\mathbf{E}$, we observe three peaks. This suggests a structural change, as does the XRPD spectra. The large peak around $82.5 \mathrm{ppm}$ is around $60 \%$ of the total signal and the other two small peaks at $\sim-84$ and $-86 \mathrm{ppm}$ make up the other $40 \%$ of the signal. The peak at $-84 \mathrm{ppm}$ diminishes with increasing time of ammonium nitrate treatment. ${ }^{1} \mathrm{H}^{-2}{ }^{29} \mathrm{Si}$ experiments give only the peak at $-82.5 \mathrm{ppm}$, suggesting only this Si site is located in close proximity of a hydrogen (from a hydronium, water or hydroxide species). Again, further investigation by ${ }^{1} \mathrm{H}$ NMR will provide a more complete picture of these structural details in these phases.
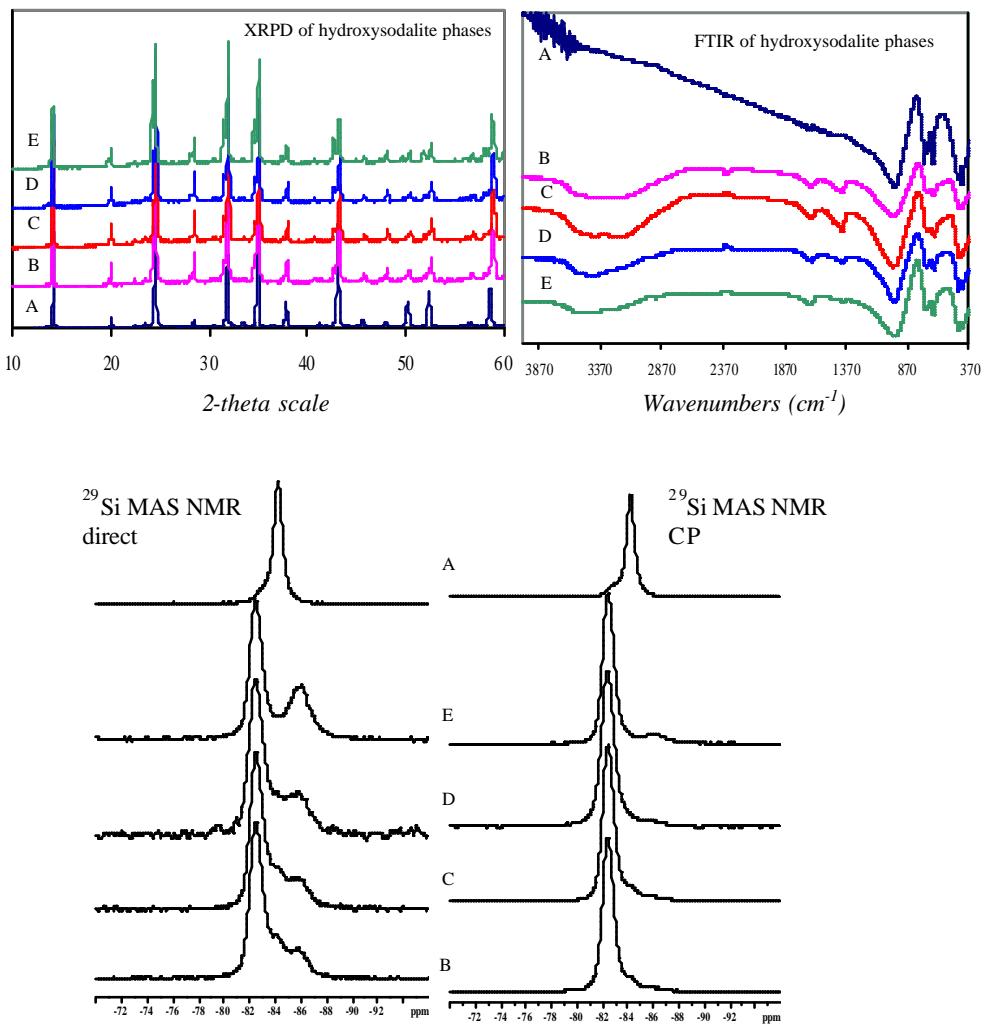

Figure 1. Spectroscopic characterizations of hydroxysodalites. 
- Unseeded batch kinetic crystallization experiments starting with extremely alkaline mixtures ( $\mathrm{pH} € 13.2)$ having a $\mathrm{Si} / \mathrm{Al}$ molar ratio of 1 , with an approximate concentration of $1 \mathrm{wt} \%$ for $\mathrm{Si}$ and $\mathrm{Al}$ and $7 \mathrm{wt} \% \mathrm{NO}_{3}{ }^{-}$Upon mixing the starting solutions, an gel-like aluminosilicate precipitate forms immediately even at room temperature. At $73^{\circ} \mathrm{C}$ (see figure 2), the gel-like precipitate transforms into crystalline zeolite $\mathrm{A}$ after approximately 3 hours of reaction; a pure and very well crystallized zeolite A phase is obtained after 7 hours. Zeolite A will then transform gradually into Sodalite. At this temperature, zeolite $\mathrm{A}$ is totally consumed after two days. At $73^{\circ} \mathrm{C}$, the sodalite phase appears to be fairly stable under those conditions as only traces of $\mathrm{NO}_{3}$ cancrinite are detected after five days. Subsequent sampling of this $73^{\circ} \mathrm{C}$ run indicates approximately less than $10 \mathrm{wt} \%$ after a month. At a lower temperature of $54^{\circ} \mathrm{C}$, the reactions proceed in a similar way and samples taken after 5, 12 and 26 days are virtually indistinguishable and contain more than 95 wt $\%$ sodalite with only traces of cancrinite. At $90^{\circ} \mathrm{C}$, however, the conversion of sodalite to cancrinite occurs at a much higher rate and both phases are present in approximately equal amounts after two weeks of experiment. Long-term reactions are currently under way in order to measure by XRPD, Rietveld refinement, and solution chemistry the molar ratios of those phases at equilibrium and to estimate the order of the reaction. Chemical analyses of the supernatant solutions show the expected a gradual decrease in the concentration of both $\mathrm{Si}$ and $\mathrm{Al}$ in the solutions as a function of time. However, the kinetics of crystallization of the considered starting solution concentrations is too fast to allow a reliable measurement of component concentrations during the initial stages of the reaction. We plan to repeat these experiments using more diluted starting solutions to decrease the reaction rates. Reference patterns of pure sodalite and cancrinite samples that were synthesized for thermodynamics properties measurements are presented figure 3; many diffraction peaks are common to both phases but the presence of cancrinite is easily evidenced by the peaks at 18.9 and $27.5 \mathrm{deg}$ (strongest peak) in 2 theta. Future batch kinetic experiments will be allowed to eventually reach equilibrium with respect to the most stable phase. Compositional evolution of the solution with time will be monitored by periodic sampling of fluids. The composition of these will be compared to long-term solubility experiments based on seeded cancrinite runs. 


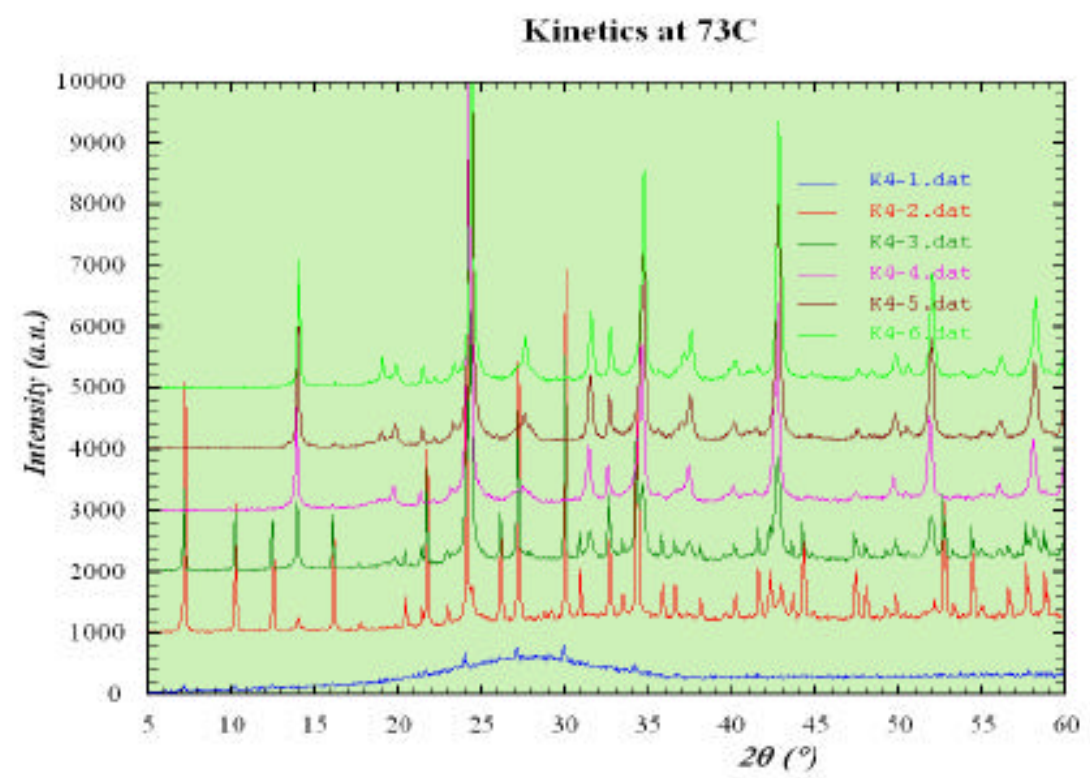

Figure 2. Reaction times at $73^{\circ} \mathrm{C}$ (bottom to top): $3 \mathrm{hrs}, 7 \mathrm{hrs}, 21 \mathrm{hrs}, 2$ days, 5 days, 30 days.

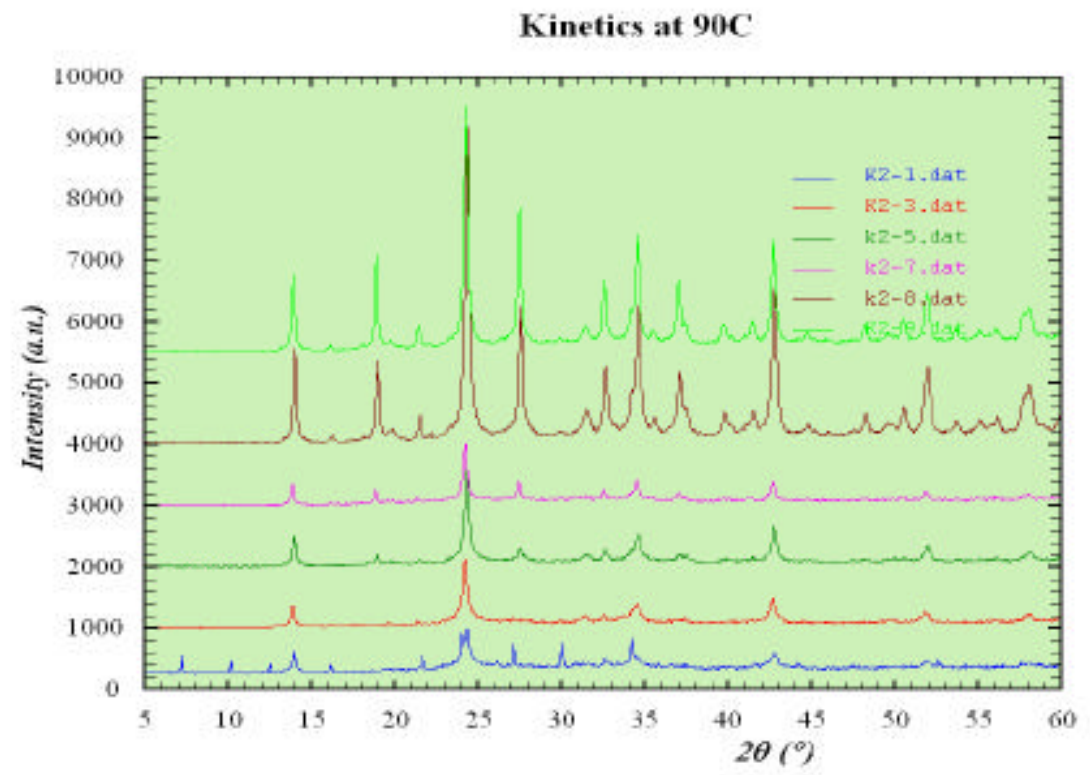

Figure 3. Reaction times at $90^{\circ} \mathrm{C}$ (bottom to top): $90 \mathrm{~min}, 4 \mathrm{hrs}, 22 \mathrm{hrs}, 5$ days, 13 days, 37 days.

- Calorimetric Studies: Complete compositional analyses of nitrate cancrinite and nitrate sodalite samples have been performed. Drop solution calorimetry experiments are finished and the heats of formation of these materials are calculated. Heat capacity measurements are conducted on nitrate cancrinite samples. However, it is found that all samples have carbon contamination problems (perhaps carbonate substituting for nitrate) to various degrees. The 
nitrogen contents are also not stoichiometric compared to ideal formulae. Thus, heat of formation data vary from sample to sample. The factors which determine the composition of a given sample produced during a given synthesis (in the lab or in tank waste) need further investigation. It is indicated that the nitrate in these materials evolves as gaseous species according to calorimetric studies, weight loss experiments, and evolved gas analysis (EGA). The gaseous products include $\mathrm{NO}_{2}$ and $\mathrm{NO}$. There is evidence that the final state of nitrate is consistent for different samples and molten salt solvents in high temperature oxide melt calorimetry experiments. Nitrate cancrinite samples are synthesized both in a lab oven and in a Setaram C-80 microcalorimeter.. The product particles are porous spherical crystals demonstrating yarn-ball structures. The porous structure raises difficulty in sample preparation for microprobe analysis due to difficulty in calcinations. In situ calorimetry experiments show that the precipitation temperature and degree of crystallization of nitrate cancrinite depend on heating rate. Slower heating rates lead to lower crystallization temperatures and longer precipitation periods. Typical precipitation temperatures vary from about 90 to $70{ }^{\circ} \mathrm{C}$ and crystallization spans from a few hours to about ten hours for heating rates of 0.1 to $0.01 \mathrm{~K} / \mathrm{min}$. HRTEM has been applied to the reaction products obtain to characterize the structure and morphology of crystalline phases at the nanoscale.

- ${ }^{29} \mathrm{Si},{ }^{27} \mathrm{Al}$, and ${ }^{23} \mathrm{Na}$ MAS NMR studies. The task of solid sample characterization with ${ }^{29} \mathrm{Si},{ }^{27} \mathrm{Al}$, and ${ }^{23} \mathrm{Na}$ MAS NMR has been completed:

1. NMR characterization of $\mathrm{NO}_{3}$ cancrinite, sodalite, hydroxy sodalite, zeolite $\mathrm{A}$, and aluminosilicate gels.

2. Studied the effects of $\mathrm{NaOH}$ and $\mathrm{NaNO}_{3}$ on the $\mathrm{Si}$ environment of Aluminosilicate precipitation.

3. Implementation of $1 \mathrm{H}-23 \mathrm{Na}$ CPMAS experiments.

4. Studied the solid formed from batch kinetic experiments from a $55^{\circ} \mathrm{C}$ experiment with ${ }^{29} \mathrm{Si}$ MAS NMR.

The task of high resolution study of aluminosilicate precipitation using NMR is completed:

1. Initial ${ }^{29} \mathrm{Si} \mathrm{NMR}$ investigation of $\mathrm{Si}$ speciation in solutions having a Si:Al 3:1 ratio for different components of tank simulant.

2. Determination of suitable concentration of $\mathrm{Al}$ and $\mathrm{Si}$, and reaction temperature to monitor precipitation with ${ }^{2} 7 \mathrm{Al}$ NMR in tank simulant. An example of the results obtained in these precipitation kinetic experiments shows the effect $\mathrm{NaOH}$ on the precipitated solid. In figure 4, the ${ }^{29} \mathrm{Si}$ MAS NMR spectra of precipitated solids formed from solutions with and without $\mathrm{NaOH}$. Solids precipitated from solutions containing $\mathrm{NaOH}$ have a ${ }^{29} \mathrm{Si}$ chemical shift that is slightly downfield of the precipitate formed without $\mathrm{NaOH}$ present in the solution. 


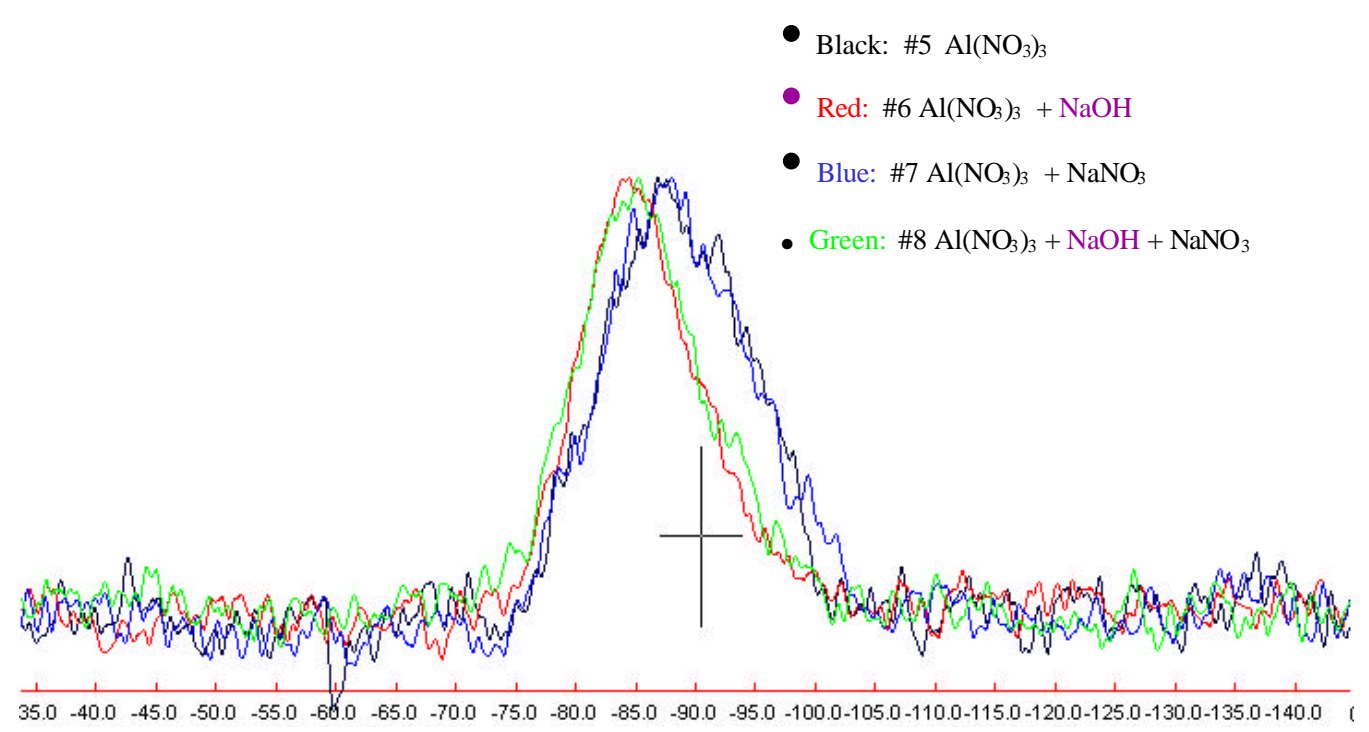

Figure 4. ${ }^{29}$ Si MAS NMR spectra of precipitated solids from solutions with and without $\mathrm{NaOH}$.

Other investigations with NMR encompassed the implementation of ${ }^{1} \mathrm{H}_{-}{ }^{23} \mathrm{Na}$ cross-polarization (CP) MAS NMR experiments. It was hoped that this technique would make possible a distinction between cancrinite and sodalite, by differentiating the local state of $\mathrm{Na}^{+}$present in the respective frameworks. For the sodalite (figure 5) sample there was no distinction between the ${ }^{1} \mathrm{H}_{-}{ }^{23} \mathrm{Na} C P M A S$ and direct ${ }^{23} \mathrm{Na}$ NMR spectra. This observation indicatines that protons, in the form of $-\mathrm{OH}$ or $\mathrm{H} 2 \mathrm{O}$, are spatially near all the $\mathrm{Na}^{+}$of this material.

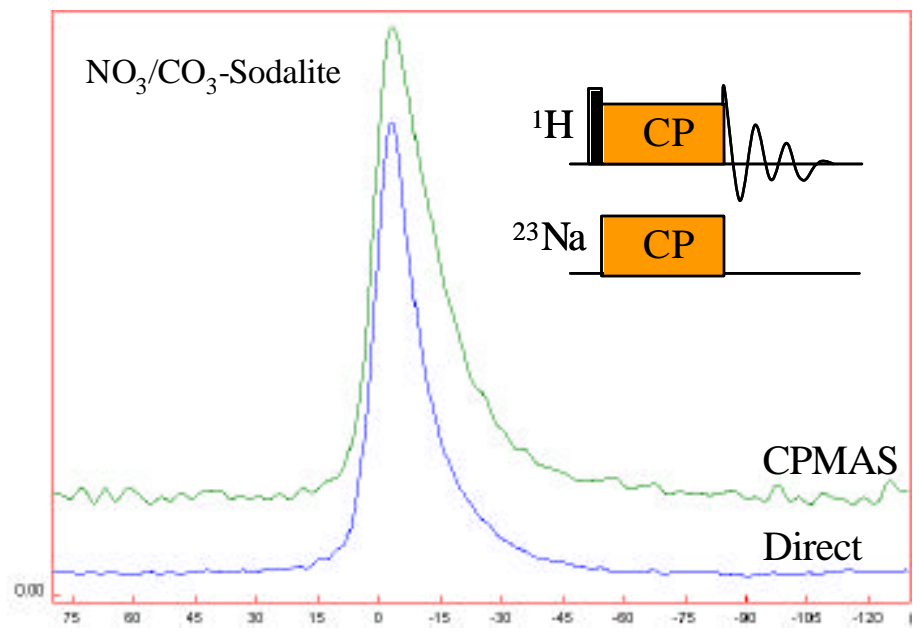

Figure 4. ${ }^{1} \mathrm{H}^{23} \mathrm{Na}$ CPMAS and direct ${ }^{23} \mathrm{Na}$ NMR spectra of sodalite synthesis. Compositional analysis of this revealed carbonate contamination. 
Future NMR studies will involve the characterization of $\mathrm{OH}$ and $\mathrm{NO}_{3}$ in hydroxy sodalite samples subjected to different treatments.

- Preliminary ion exchange experiments on cancrinite using different matrix electrolytes and temperatures indicated the strong partitioning of $\mathrm{Cs}^{+}$relative to anions such as $\mathrm{ReO}_{4}{ }^{-}, \mathrm{SeO}_{4}{ }^{--}$, and $\mathrm{I}^{-}$. More ion exchange experiments are planned to study this behavior on aluminosilicate phases under various chemical conditions. Within the last year, our laboratory acquired new analytical facilities such as an ICP-MS and ion chromatography (IC). Also, the laboratory underwent major changes in the incorporation of new storage and benchtop units. Given the new analytical capabilities, we have been involved in developing a methodology to analyze the composition of aluminosilicates. This is important given the difficulties encountered by the group at UC Davis in using electron microprobe analysis to obtain an accurate determination of the composition of run products. Our ongoing effort in perfecting an analytical methodology using ICP-MS has proven productive in generating encouraging results. Moreover, routine analysis of aqueous solutions using ICP-MS has been achieved.

- Thermodynamic modeling: The incorporation of Pitzer parameter data for the system $\mathrm{Na}-\mathrm{NO}_{3}-\mathrm{Al}(\mathrm{OH})_{4}-\mathrm{SiO}_{2}-\mathrm{H}_{2} \mathrm{O}-\mathrm{OH}$ up to $100^{\circ} \mathrm{C}$ into a database usable by the computer code EQ3/6 has been completed. Encouraging results have been obtained in the prediction of amorphous silica, soda niter, gibbsite solubility from parameters obtained from literature data to the desired temperature range. Nevertheless, further refinements of this data and validation tests are still under way. Composition of solutions obtained from solubility and kinetic experiments will be used with this code and database for the estimations of species activity as a function of salt concentration and temperature. Ongoing work includes the use of the aqueous speciation results to define the solubility of these phases and develop a reaction path scheme that describes its formation under various temperatures and solution compositions.

2. Planned Activities: Future and/or planned research activities related to work remaining or in progress are as follows:

- Continuation of $\mathrm{NO}_{3}$ cancrinite and $\mathrm{NO}_{3}$ sodalite solubility, phase characterization, and precipitation kinetic studies. Emphasis is given to produce a pure $\mathrm{NO}_{3}$ sodalite phase. The batch kinetic precipitation studies will be conducted at various temperature and solution compositions. Phase characterization of run products will be performed routinely in these experiments.

- Preparation of a manuscript on the solubility, synthesis, thermochemistry and characterization of $\mathrm{NO}_{3}$ cancrinite for submission in a peer-review scientific journal.

- Continuing ion exchange experiments on cancrinite and sodalite at various temperatures and electrolyte matrices.

- Use and interpretation of thermochemical and solubility experimental data to generate activity phase diagrams and develop a predictive model for the formation of cancrinite is under way. Refinements of the Pitzer parameters is 
also continuing to conduct an accurate description aqueous speciation of tank waste solutions.

- Ongoing activities include identification of nitrogen-containing gas phases and examination of the consistency of gaseous products using EGA and solution calorimetry. Heat capacity measurements are yet to be performed on nitrate sodalite sample once carbon contamination problem is solved. Fine-tuning of composition and calorimetry data based on improved experimental techniques is necessary. Energetics of ion exchange reactions of the aluminosilicate materials will also be investigated. Two publications (one is on the energetics of nitrate cancrinite and nitrate sodalite and the other is on the in situ synthesis of nitrate cancrinite) are proposed for preparation. We are planning to direct some of our in situ calorimetry activities to study the aggregative growth of nano-sized particles.

3. Information Access: N/A

4. Optional Additional Information: N/A

5. Optional Proprietary Information: N/A 